\title{
MIĘDZY TEKSTEM KULTURY A PRAKTYKA KLINICZNĄ. NARRACJE O PSYCHIATRACH A AKTUALNE PROBLEMY DYSCYPLINY
}

Anna Róża Hoss

Instytut Kultury Polskiej UW
Institute of Polish Culture,
University of Warsaw
annarozahoss@gmail.com
ORCID: 0000-0001-8615-7284

\section{WPROWADZENIE}

Ekspansja kategorii narracji w naukach humanistycznych ułatwiła eksplorację pozornie odległych przestrzeni, w tym medycyny ${ }^{1}$. Opowiadanie historii jest jednym z czynników konstytuujących chorobę, rozumianą jako fenomen transdyscyplinarny. Narracja kształtuje indywidualne doświadczenie chorowania i je dialogizuje, włączając kolejnych aktorów oraz oferując doświadczenie zastępcze ${ }^{2}$. Wieloaspektowość roli narracji staje

1 Przykładem może być rozkwit podejścia medycyny narracyjnej, zachęcającej lekarzy (przede wszystkim innych specjalizacji niż psychiatria, dla której to podstawowe narzędzie pracy) do potraktowania narracji pacjenta o jego doświadczeniu choroby jako potencjalnej zmiennej lub narzędzia. Zob. R. Charon, Narrative Medicine. Honoring the Stories of Illness, New York 2006; eadem, The Narrative Road to Empathy, [w:] H. Spiro, M.G. McCrea Curnen, E. Peschel, D. St James, Empathy and the Practice of Medicine: Beyond Pills and the Scalpel, New Haven 1993; Medycyna narracyjna. Opowieści o doświadczeniu choroby w perspektywie medycznej i humanistycznej, red. M. Chojnacka-Kuraś, Warszawa 2019; A. Kleinman, The Illness Narratives: Suffering, Healing, and the Human Condition, New York 1988; V. Skultans. Anthropology and Narrative, [w:] Narrative Based Medicine. Dialogue and Discourse in Clinical Practice, eds. T. Greenhalgh, B. Hurwitz, London 1998.

2 W teorii społecznego uczenia się Alberta Bandury uczenie się wielu zachowań zachodzi poprzez modelowanie. Obserwacja modela otrzymującego pozytywne wzmocnienie zachowania sama w sobie jest pozytywnym wzmocnieniem tego zachowania u obserwatora. Stąd uczenie się nie zachodzi wyłącznie 
się wyraźniejsza w przypadku zaburzeń, w których praktyki opowiadania stanowią przedmiot obserwacji i metodę interwencji ${ }^{3}$. Narracje o psychiatrach są dialogiczne w szerokim sensie. Cyrkulujące w nich mity i symbole pozostają w intensywnej interakcji z każdym - również hipotetycznym i pośrednim - uczestnikiem relacji terapeutycznej. Chętnie wykorzystywane w różnorakich dyskursach kultury, zwłaszcza popularnej, tworzą obraz jednocześnie zdeformowany i spójny, a przede wszystkim stanowiący główne źródło wiedzy o dziedzinie i jej przedstawicielach ${ }^{4}$. Konsekwentnie reprodukując stereotypy, autentycznie kształtują kondycję psychiatrii, wpływają na jej rozwój, dostępność i sposób postrzegania.

Niniejszy tekst jest próbą wskazania potencjalnych zależności między filmowymi narracjami o psychiatrach, osadzonymi w aktualnym kontekście historyczno-kulturowym, a problemami dziedziny i ich wypadkową - stanem zdrowia pacjenta. Na potrzeby pracy przyjmuję szeroką, Brunerowską ${ }^{5}$ definicję narracji, w której medium jest kwestią drugorzędną. W pierwszej części analizy proponuję podstawową siatkę pojęć, przydatną do przybliżenia fundamentów zjawiska. Wyjściowym materiałem badawczym będzie typologia filmowych postaci psychiatrów, której autorami są Glen i Krin Gabbardowie. Klasyfikacja ta, oparta na wyczerpującym przeglądzie obrazów filmowych, pozwoli na usystematyzowanie znaków w ich sensie referencyjnym i posłuży za punkt wyjścia do interpretacji funkcji komunikacyjnej. Przywołam kilka zestawów znaków o różnych poziomach złożoności i zastanowię się, do jakich wartości i ideologii odsyłają. Poruszę wątki piętna, płci, widzialności, spójności oraz dewaluacji i idealizacji.

Druga część niniejszego artykułu obejmuje analizę recepcji narracji. Spróbuję osadzić je w kontekście społecznym, koncentrując się na kilku

wskutek bezpośrednich doświadczeń, ale i pośrednich, cudzych - zastępczych; zob. A. Bandura, Teoria społecznego uczenia się, Warszawa 2007.

3 A. Kapusta, Performowanie szaleństwa: narracja i choroba psychiczna, [w:] Performatywne wymiary kultury, red. K. Skowronek, K. Leszczyńska, Kraków 2012, s. 209-223.

${ }^{4}$ L. Beachum, The Psychopathology of Cinema: How Mental Illness and Psychotherapy are Portrayed in Film, „Honors Projects” 2010, Vol. 56.

5 J.S. Bruner, Życie jako narracja, „Kwartalnik Pedagogiczny” 1990, nr 2, s. 4. 
aktualnych problemach psychiatrii. Uznaję za nie: wzrost liczby osób nieotrzymujących wymaganej pomocy, zwiększenie liczby chorych, utrzymującą się społeczną niechęć wobec leczenia psychiatrycznego, ale także wewnętrzną degradację dyscypliny, powiązaną ze stygmatyzacją i autostygmatyzacją jej przedstawicieli i osób korzystających z ich wsparcia. W tym miejscu pozwolę sobie na przywołanie kilku konkluzji z literatury przedmiotu o charakterze empirycznym. Porównując wnioski, zaproponuję kilka wspólnych obszarów problemowych, ujawniających się na etapach dystrybucji, konsumpcji i recepcji tekstu kultury. Poruszę kwestię mechanizmu autostygmatyzacji, unaoczniającego cyrkularny charakter problemu. Należy tu zaznaczyć, że materiał badawczy cechuje się specyficznymi ograniczeniami ${ }^{6}$. Ze względu na ograniczoną objętość pracy koncentruję się przede wszystkim na postaci lekarza psychiatry, mniej na psychiatrii jako dyscyplinie. Nie rozwijam zagadnienia sposobów przedstawiania pacjenta, choroby czy pozostałych specjalistów z dziedziny zdrowia psychicznego. Finalne wnioski dotyczące ogólnej kondycji psychiatrii są zaś - rzecz jasna hipotezami, otwierającymi pole do dalszych badań.

\section{PSYCHIATRIA W FILMIE}

Psychiatria w obrazach filmowych, w porównaniu do innych subdyscyplin medycyny, jest obiektem najintensywniejszej stereotypizacji. O ile komunikaty w mediach masowych można nazwać jednoznacznie negatywnymi, o tyle filmowe obrazy psychiatrii sytuują się zwykle na krańcach kontinuum „dewaluacja - idealizacja”. Treści przekazywane za pomocą mediów masowych, w tym fikcyjne, pozostają podstawowym źródłem potocznej

${ }^{6}$ Literatura przedmiotu dotyczy przede wszystkim kontekstu amerykańskiego. W Polsce kwestie związku psychiatrii z kinem porusza m.in. Wojciech Otto; zob. idem, Wizerunki bohaterów z chorobami psychicznymi w polskim kinie, [w:] Medycyna w filmie, red. M. Ganczar, M. Oleszczyk, Kraków 2017. W wielu źródłach nie dokonuje się (zasadniczego z perspektywy socjologii medycyny) rozróżnienia między psychiatrą, psychologiem i psychoterapeutą.

7 N. Sartorius, Guidance on how to Combat Stigmatization of Psychiatry and Psychiatrists, „World Psychiatry” 2012, Vol. 11, No. 1, s. 61-62. 
wiedzy o dyscyplinie ${ }^{8}$. Wyniki badań empirycznych wskazują na istnienie bezpośredniej zależności między sposobem przedstawiania psychiatrii i psychiatrów w mediach a społecznym nastawieniem do chorób psychicznych, jakością życia doświadczających ich osób, a nawet decyzjami na szczeblu rządowym ${ }^{9}$. Elementy narracji filmowych przedostają się do przekazów dziennikarskich, zacierając granicę między fikcją a faktem. Ilustruje to tendencja do zestawiania wątku choroby psychicznej z wątkiem przemocy ${ }^{10}$. Metodycznie powielane stereotypy ewoluują we względnie stabilne, funkcjonujące w imaginarium społecznym uprzedzenia. Nieprzychylne, zniekształcone, latentne reprezentacje poznawcze kształtują postawy, motywacje i oczekiwania względem leczenia. Negatywne wizerunki psychiatrów są przydatne do takiego sposobu objaśniania rzeczywistości, który sprzyja realizacji partykularnych interesów. Mogą utrwalać pozycję klasy dominującej, regulując dostęp do usług z zakresu ochrony zdrowia psychicznego. Bez wątpienia jednak stanowią źródło potencjalnych interwencji korygujących, co czyni je ponadprzeciętnie istotnym materiałem badawczym ${ }^{11}$.

Fluktuacje obrazu psychiatrów w kinie XX wieku pozostają w ścisłej zależności z kontekstem historycznym. Sekwencje dewaluacji i idealizacji korelują ze społecznymi nastrojami względem dziedziny. Taktyki opowiadania są ustanawiane w relacji z bieżącą sytuacją polityczną. Dotyczy to zwłaszcza stopnia akceptacji dyscypliny przez aparat państwowy, a co za tym idzie - poziomu dofinansowania jej zaplecza akademickiego, jak i priorytetowości powszechnego dostępu do jej usług. Nie bez znaczenia pozostają epizody hossy w sferze wynalazczości i modernizacji. Uwarunkowania te

${ }^{8}$ G. Walter, A. McDonald, J. Rey, A. Rosen, Medical Student Knowledge and Attitudes Regarding ECT Prior to and After Viewing ECT Scenes from Movies, „The Journal of ECT” 2002, Vol. 18, No. 1, s. 43-46.

9 D.R. Edney, Mass Media and Mental Illness: A Literature Review, Canadian Mental Health Association, Ontario 2004, https://ontario.cmha.ca/wp-content/ files/2012/07/mass_media.pdf [dostęp 11.08.2019].

${ }_{10}$ M. Matas, N. El-Guebaly, A. Peterkin [et al.], Mental Illness and the Media: An Assessment of Attitudes and Communication, „The Canadian Journal of Psychiatry" 2017, Vol. 30, No. 1, s. 12-17.

${ }^{11}$ G. Walter, The Stereotype of the Mad Psychiatrist, „Australian and New Zealand Journal of Psychiatry" 1989, Vol. 23, s. 547-554. 
określają treść moralnej oceny dyscypliny i jej praktyk. Ubiegłe stulecie otwierają więc serie frenetycznych obrazów rozliczających się z psychiatrią przednaukową i jej niechlubnym dorobkiem, jeszcze świeżym w kolektywnej pamięci (np. Dr Dippy’s Sanitarium [1906], prod. American Mutoscope Company). Nawarstwienie dowartościowujących, a wręcz afirmatywnych narracji towarzyszy okresom wzrostu przydatności dziedziny, jak w przypadku filmów z okresu okołowojennego (np. Ludzie-koty [The Cat People], 1942, reż. Jacques Tourneur; Trzy kamelie [Now, Voyager], 1942, reż. Irving Rapper; Lady in the Dark, 1944, reż. Mitchell Leisen; Pod jednym sztandarem [Home of the Brave], 1949, reż. Mark Robson). Służba ofiarom i kombatantom drugiej wojny światowej pozwala psychiatrii spłacać dług zaciągnięty przez jej pionierów. „Złoty okres” (1956-1962; np. Nagle, zeszłego lata [Suddenly, Last Summer], 1959, reż. Joseph L. Mankiewicz; Wiosenna bujność traw [Splendour in the Grass], 1961, reż. Elia Kazan; The Mark [1961], reż. Guy Green; David and Lisa [1962], reż. Frank Perry; Pressure Point [1962], reż. Hubert Cornfield) zostaje zneutralizowany strumieniem narracji radykalnie antypsychiatrycznych, homologicznych wobec postulatów kontrkulturowych związanych z wojną w Wietnamie (np. W przebraniu mordercy [Dressed to Kill], 1960, reż. Robert Lynn; Lot nad kukułczym gniazdem [One Flew Over the Cuckoo's Nest], 1975, reż. Miloš Forman; Szklany klosz [The Bell Jar], 1978, reż. Larry Peerce). Od końca XX wieku eksplorowane problemy nie dotyczą już zasadności istnienia dyscypliny, a roli i właściwości jej reprezentanta (np. Szaleństwo króla Jerzego [The Madness of King George], 1994, reż. Nicholas Hytner; Lepiej być nie może [As Good as it Gets], 1997, reż. James L. Brooks; Piękny umysł [A Beautiful Mind], 2001, reż. Ron Howard) ${ }^{12}$. Perypetie nie rozwijają się już na płaszczyźnie psychiatria vs świat - inspirowany labilnością narracyjną konflikt odbywa się na wewnętrznym terytorium dziedziny. Rozważenie zależności między sposobem opowiadania a aktualnym tłem historycznym może pomóc więc w próbach identyfikacji tych elementów, które „próbują przemienić historię w naturę"13.

12 M.T.B. Dubugras, J. Mari, J.F.F.Q. dos Santos, The Image of Psychiatrist in Academy Award Winning Films from 1991 to 2001, „Revista de Psiquiatria do Rio Grande do Sul” 2007, Vol. 29, No. 1, s. 100-109.

13 R. Barthes, Mitologie, tłum. A. Dziadek, Warszawa 2000, s. 100-101. 
Schyłek metanarracji ujawnia się także w dezintegracji tożsamości psychiatry. Wielość mikronaracji uwidacznia jednak pewne wzorce. Na podstawie analiz czterystu filmowych postaci psychiatrów z ubiegłego stulecia Gabbardowie wyodrębnili osiem ich typów ${ }^{14}$ (zob. tabela 1). Kategoryzację tę można rozumieć jako zbiór wariantów strategii zarządzania piętnem: rozpracowywania jego oczywistości, widoczności czy natarczywości ${ }^{15}$. Można postrzegać je również jako zestaw recept, których standaryzacja, swoista kulturze masowej, umożliwia systematyczną reprodukcję. Sześć spośród ośmiu wariantów można jednoznacznie uznać za dewaluujące.

Tabela 1. Typy filmowych psychiatrów; źródło: G.O. Gabbard, K. Gabbard, op. cit.

Dr Dippy - niekompetentny zaniedbany, brodaty, ekscentryczny mężczyzna, mówiący z europejskim akcentem. Przejawia oznaki „szaleństwa”. Realizuje mit „niebieskiego ptaka”, mit szalonego naukowca lub pełni funkcję błazna. Na przykład dr Dippy w Dr Dippy's Sanitarium.

Dr Wonderful - opiekuńczy, atrakcyjny, sympatyczny. Występuje w roli misjonarza lub cudotwórcy. Dowartościowuje rolę pacjenta: jest gotów poświęcać dla niego własne życie prywatne czy łamać zasady zawodowe. Realizuje mit dobrego pasterza lub miłosiernego samarytanina. Postać skrajnie wyidealizowana, spójna. Na przykład dr Green w Lepiej być nie może czy dr Curtis Luther w Trzech obliczach Ewy (The Three Faces of Eve, 1957, reż. Nunnally Johnson).

Dr Evil - bezwzględny, złowrogi, czarujący i uwodzicielski. Uprzedmiotawia pacjenta, wykorzystując go do osiągnięcia własnych korzyści. Narusza granice relacji pacjent lekarz. Reprezentuje makiaweliczną, redukcjonistyczną, skrajnie scjentystyczną wizję nowożytnej medycyny. Na przykład dr Hannibal Lecter w Milczeniu owiec (The Silence of the Lambs, 1991, reż. Jonathan Demme); dr Jonathan Crane w Batmanie - Poczatku (Batman Begins, 2005, reż. Christopher Nolan); dr Gideon Largeman w Powrocie do Garden State (Garden State, 2004, reż. Zach Braff).

${ }_{14}$ G.O. Gabbard, K. Gabbard, Psychiatry and the Cinema, Virginia 1999.

15 Zob. E. Goffman, Piętno. Rozważania o zranionej tożsamości, tłum. A. Dzierżyńska, J. Tokarska-Bakir, wstęp J. Tokarska-Bakir, Gdańsk 2005, s. 86. 
Societal Agent - reprezentant systemowego aparatu opresji. Jego interwencje służą przekształceniu pacjenta w jednostkę spełniającą wymogi normy społecznej i obejmują karanie, kontrolę i dyscyplinowanie. Reprezentuje problem normatywności w zdrowiu psychicznym, wątek wiedzy - władzy i instytucjonalnie uprawomocnionej przemocy. Jego pacjent to osoba oświecona, której wmawia się zaburzenie. Na przykład dr Vankay w Błękicie nieba (Blue Sky, 1994, reż. Tony Richardson); personel w Locie nad kukułczym gniazdem; psychiatra w Harold and Maude (1971, reż. Hal Ashby).

The Romantic - niezdolny do utrzymania profesjonalnych granic, angażujący się w relację romantyczną z pacjentem. Realizuje mit zakazanego owocu. Na przykład dr Constance Petersen w Urzeczonej (Spellbound, 1945, reż. Alfred Hitchcock).

Dr Sexy - kobieta w roli obiektu seksualnego, niezdolna do utrzymania profesjonalnych granic. W toku akcji uratowana przez pacjenta płci męskiej.

Odpowiednikiem tego typu jest postać uwodzącej pacjentki. Realizuje mit zakazanego owocu. Na przykład dr Helen Gurley Brown w filmie Samotna dziewczyna i seks (Sex and the Single Girl, 1964, reż. Richard Quine).

Dr Flawed - kompetentny, zaangażowany, równoważący wady i zalety. Pojedyncze akty wypadnięcia z roli paradoksalnie sprzyjają jego idealizacji. Realizuje mit pół boga, pół człowieka. Na przykład psychiatra w Psychozie (Psycho, 1959,

reż. Alfred Hitchcock).

Rational Foil - dogmatyczny, konserwatywny, nieelastyczny. Podważa wiarygodność opowieści pacjenta, która okazuje się prawdziwa. Zjawisko wskazane jako patologia ma inne, niezauważone przyczyny. Narracja podkreśla nieadekwatność prostych rozwiązań i schematów, eksploatuje pogląd solipsystyczny, często zaprzecza istnieniu chorób psychicznych. Na przykład personel w Locie nad kukułkczym gniazdem.

Proponuję uzupełnienie powyższej klasyfikacji o trzy pozycje. „Typ transparentny” reprezentowałby wątki „psychiatry bez twarzy” i „anonimowego psychiatry"16. Stosuje się tu znak niewidoczny wprost: sposób aranżacji kadru wymusza obecność wyłącznie postaci pacjenta (np. Wnętrza [Interiors], 1978, reż. Woody Allen; Zbrodnie namiętności [Crimes of Passion], 1984, reż. Ken Russell; Zostawić Las Vegas [Leaving Las Vegas], 1995, reż. Mike Figgis; Samotny facet [The Lonely Guy], 1984, reż. Arthur Hiller). Typ konotuje nieefektywność, bezradność i dwuznacznie rozumianą drugoplanowość specjalistów. Druga kategoria to „typ narcystyczny”, charakterystyczny dla produkcji ostatniego trzydziestolecia. Realizuje wprost

16 G.O. Gabbard, Psychotherapy in Hollywood Cinema, „Australasian Psychiatry" 2001, Vol. 9, No. 4, s. 365-369. 
wartości właściwe kulturze narcyzmu ${ }^{17}$. Za proces zdrowienia nie odpowiada więc psychiatria jako dyscyplina, tylko ci z jej reprezentantów, których wyróżnia ponadprzeciętność i nieszablonowość. Cechuje ich „nowoczesne" nastawienie: swobodna ekspresja emocjonalna, akceptacja postaci pacjenta, nieformalna postawa i podobne do pacjenta pochodzenie klasowe. Sugeruje to, że rozumienie aparatu psychicznego jest zajęciem wyjątkowych jednostek. Nieosiągalne dla innych, nie powinno stanowić przedmiotu zainteresowania. Tak zarysowana psychiatria nie może być rzemiosłem, a wyłącznie przedmiotem misji. Ostatnią propozycją jest „typ wypalony”. Przepracowany, zmęczony specjalista z powodu nagromadzenia obowiązków i obciążeń zaczyna uprzedmiotawiać pacjentów. Pracuje mechanicznie, odruchowo, niedokładnie i rutynowo, uosabiając wypalenie zawodowe, które może dosięgnąć każdego uczestnika neoliberalnego rynku pracy. Jednocześnie dotyka wrażliwego tematu: finansowej motywacji jednej ze stron relacji pacjent - lekarz.

Filmowe psychiatrki są nosicielkami niezbywalnego piętna „odwiecznego nakazu kobiecości”18. Mechanizm „przechodzenia od semiologii do ideologii" ${ }^{19}$ widać wyraźnie właśnie na przykładzie dwóch typów kobiecych: The Romantic i Dr Sexy. Oba typy eksponują atrybuty kojarzone z atrakcyjnością fizyczną, która pełni funkcję piętna i nie może zostać zakryta wizerunkiem profesjonalnym. Ich wspólną cechą jest brak umiejętności kontroli własnego zachowania (zwłaszcza w ramach ekspresji erotycznej czy emocjonalnej) i utrzymania etycznych granic w relacjach $\mathrm{z}$ pacjentem mężczyzną. Wątek wiedzy - władzy ${ }^{20}$, obecny praktycznie w każdej narracji

17 C. Lasch, The Culture of Narcissism: American Life in An Age of Diminishing Expectations, New York 1991, s. 232.

18 R. Barthes, op. cit., s. 81.

19 Ibidem.

20 „Wiedza - władza” - termin pochodzący z teorii kultury Michela Foucaulta, odnoszący się do nowoczesnych, właściwych ładowi kapitalistycznemu technik dyscyplinarnych; zob. M. Foucault, Słowa i rzeczy. Archeologia nauk humanistycznych, tłum. T. Komendant, Gdańsk 2005; M. Herer, Michela Foucaulta wizja współczesności. Wiedza, władza i gry prawdy, http://www.ekologiasztuka.pl/pdf/ f007herer.pdf [dostęp 19.04.2020]; A. Kapusta, Filozofia ekstremalna. Wokót myśli krytycznej Michela Foucaulta, Lublin 2002; J. Kochanowski, Wiedza jako władza 
o psychiatrii, w opowieści o kobiecie służy wyłącznie wyjaskrawieniu mitu hybris. Wiedziona pychą bohaterka próbuje realizować się w roli zawodowej stereotypowo uważanej za męską. Jej niekompetencja i nieumiejętność adekwatnej oceny własnych możliwości narażają ją, a czasem i jej pacjenta, na niebezpieczeństwo. W toku fabuły zostaje skonfrontowana ze swoją małością, ponosi porażkę i wyciąga wnioski dotyczące własnych kompetencji, siły i przynależnego jej miejsca. Postać Dr Sexy jest sprowadzona do roli obiektu seksualnego. Nie potrafiąc powstrzymać swojego pociągu, psychiatrka przekracza kolejne granice relacji terapeutycznej, rozpoczynając relację seksualną z pacjentem. On, mimo że w wyniku pomyłki lub w chwili słabości znalazł się w pozycji biernej, ostatecznie przemienia się w głównego bohatera, ratując lekarkę przed efektami jej własnych błędów.

W typie romantycznym intensywniej eksponuje się figurę kobiety matki lub kobiety żony. Niemożliwą do opanowania siłą jest już nie czysty pociąg erotyczny, a miłość. Towarzysząca narracja „katartycznego uzdrowienia” wprowadza wartość faworyzowaną przez kulturę (tu: miłość romantyczną) w miejsce właściwego leku. Będąc poza intencją i kontrolą leczącej, przedstawia psychiatrię jako rodzaj sztucznej (a więc w domyśle: gorszej) interwencji w świat emocjonalny, który powinien pozostać spontaniczny. Bezkonkurencyjny w kulturach indywidualizmu mit romantycznej miłości występuje przeciwko mitowi nowożytnej nauki. Rozgrywając tyleż niebezpieczne, ile przezroczyste opozycje (natura - kultura, ziemskie - nadprzyrodzone, ciało - dusza), unaocznia potencjalność uleczenia, a bezdyskusyjnie odmawiając bohaterce sprawczości, ostrzega przed konsekwencjami hybris. Tak realizowana trywializacja choroby może być brzemienna w skutkach dla odbiorcy niezależnie od płci. Mężczyzna dowiaduje się z tej opowieści, że co prawda pewien stopień cierpienia w momentach kryzysu jest dopuszczalny (podobnie jak popełnienie błędu poszukiwania pomocy u kobiety), jednak ostatecznie jego zadaniem jest samodzielne rozwiązanie problemu. Pacjent, reprezentując antagonistycznie nastawione środowisko pozaeksperckie, przeciwstawia nowożytnej medycynie wartości uniwersalne, przyrodzone, ponadparadygmatyczne, odsłaniając jej słabości i unieważniając swój lęk przed dzierżycielem wiedzy - władzy. Zaburzenie psychiczne zostaje, jeśli

i wiedza jako opór. Wokót koncepcji Marka Olssena, Johna Codda i Anne-Marie O’Neill, „Nauka i Szkolnictwo Wyższe” 2007, nr 1 (29). 
nie całkowicie zanegowane, to drastycznie odmedykalizowane i przetłumaczone na język potoczny. Psychiatrka, jako nieracjonalna, nieskuteczna, niesamodzielna, uosabia wizję psychiatrii jako poddziedziny zdyskredytowanej przez inne nauki. „Symboliczne unicestwienie kobiety” i w tym wypadku dąży do „podtrzymania i kontynuacji istniejącego podziału pracy zdeterminowanego przez ortodoksyjne wyobrażenia o kobiecości” i „służy potwierdzaniu ich roli jako żon, matek i gospodyń domowych"21. W interesie patriarchalnego systemu leży przekonanie odbiorcy, że niemożność realizacji zawodu na równi z mężczyzną jest wynikiem uniwersalnej, kobiecej natury. Tezę tę potwierdza nie tyle moment porażki postaci, ile raczej to, co następuje przed nim. System bowiem udostępnił bohaterce możliwość edukacji i wkroczenia na rynek pracy, a mimo to poniosła ona klęskę. Tak skonstruowana opowieść bagatelizuje wpływ czynników ekonomicznych, psychologicznych, społecznych i kulturowych, utrwalając patriarchalne stosunki władzy.

Wygląd zewnętrzny postaci psychiatrów filmowych często odsyła do kategorii niespójności, zachęcając do poszukiwania symboli piętna. Większość z nich to białoskórzy mężczyźni w średnim wieku. Wielu z nich ma elementy wyglądu wprost zapożyczone od Zygmunta Freuda: okulary, zarost, garbaty nos, formalny strój. Zwykle nie noszą białego fartucha, a mimo to ich stroje komunikują przynależność do grupy hermetycznej, uprzywilejowanej, rozpoznawalnej i ekskluzywnej, legitymizując obecność profesjonalnego zaplecza i wymuszając uległą postawę pacjenta. Wycyzelowany ubiór miewa jednak drobne skazy: przetarcia czy zabrudzenia, w dosłowny sposób komunikujące o fakcie, cesze czy zjawisku, które mając źródło w pozaprofesjonalnej codzienności, poświadczają istnienie prywatnego życia lekarza. W przypadku postaci negatywnej może być to sygnałem o porzuceniu zainteresowania własną fizycznością, w wielu kulturach kojarzonym z kosztem intensywnej pracy intelektualnej. Psychiatra mężczyzna nie potrafi lub nie musi przyjmować konformistycznej postawy względem wymogu atrakcyjności. Wspomniana nieczęsta obecność najbardziej oczywistego znaku przynależności do środowiska medycznego - białego kitla - komunikuje odrębność psychiatrii wśród dyscyplin medycznych, tak istotną, że

${ }^{21}$ G. Tuchman, The Symbolic Annihilation of Women by the Mass Media, cyt. za: D. Strinati, op. cit., s. 147. 
aż wymuszającą rezygnację z silnego symbolu prestiżu. Ukrywanie piętna można w tym kontekście uznać za rodzaj nieuczciwej gry z pacjentem. Sam przedmiot zainteresowania, a często i metody oddziaływania dziedziny są transparentne. Narzędzia pracy lekarzy zajmujących się chorobami somatycznymi są w większości widoczne w oczywisty sposób. Podmiot wie, kiedy staje się przedmiotem - obiektem badania. Ukrycie tożsamości przez psychiatrę może uniemożliwić świadomą, dobrowolną zgodę na udział w badaniu. Problematyczność natury przedmiotu i narzędzi psychiatrii to jeden z przykładów powracającego tematu przekształceń i kryzysów w nauce. Jest to kolejna kanwa do dyskusji nad podważaniem dylematu psychofizycznego czy nad kryzysem przekonania o homogeniczności lub heterogeniczności nauki.

\section{ZWIERZĘ SAMOINTERPRETUJĄCE SIĘ. TOŻSAMOŚĆ W PRAKTYCE}

W 2010 roku World Psychiatric Association wydaje dokument, w którym instruuje, jak wa lczyć (combat) ze stygmatyzacją psychiatrii i psychiatrów; pięć lat później podobna publikacja zachęca do poprawiania (improve) wizerunku ${ }^{22}$. Społeczne postawy wobec psychiatrii ulegają systematycznemu, powolnemu polepszeniu, jednak nadal są gorsze niż w przypadku innych dziedzin medycyny ${ }^{23}$. Wielopłaszczyznowe połączenie kwestii tożsamości ze zjawiskiem stygmatyzacji stanowi a u to st yg m at y z acja, rozpoznawana jako poważny problem dziedziny.

Pacjenci uważają psychiatrów za lekarzy skłonnych do manipulacji i naruszania granic, nieskutecznych, zarozumiałych, wyróżniających się największą dziwacznością. Nie pozostaje to bez związku z faktem, że równolegle do globalnie wzrastającego zapotrzebowania na pomoc psychiatryczną

22 D. Bhugra, N. Sartorius, A. Fiorillo [et al.], EPA Guidance on how to Improve the Image of Psychiatry and of the Psychiatrist, „European Psychiatry” 2015, Vol. 30, s. 423-430; N. Sartorius, W. Gaebel, H.-R. Cleveland [et al.], WPA Guidance on how to Combat Stigmatization of Psychiatry and Psychiatrists, „World Psychiatry” 2010, Vol. 9, s. 131-144.

${ }^{23}$ N. Sartorius, W. Gaebel, H.R. Cleveland [et al.], op. cit., s. 61-62. 
około trzy czwarte osób wymagających takiej opieki nie otrzymuje jej ${ }^{24}$. Podstawowymi czynnikami pozaekonomicznymi odsuwającymi ludzi od leczenia są lęk przed stygmatyzacją, wstyd, brak wiary w skuteczność leczenia oraz własne uprzedzenia wobec psychiatrów i osób chorujących psychicznie.

Reprezentanci pozostałych dyscyplin medycznych mówią o psychiatrach jako o osobach mniej stabilnych emocjonalnie, neurotycznych, nieskutecznych, a nawet bezużytecznych ${ }^{25}$. Status psychiatry jest niski nie tylko wśród innych lekarzy, naukowców, ale i wśród specjalistów z zakresu zdrowia psychicznego w ogóle ${ }^{26}$. Studenci medycyny opisują psychiatrów podobnie jak osoby bez wykształcenia kierunkowego, co może implikować prawdopodobnie wspólne źródło stereotypów ${ }^{27}$. Portretują ich jako nieskutecznych ekscentryków, reprezentujących dziedzinę wewnętrznie skłóconą i niedostatecznie naukową ${ }^{28}$. Werbalizują również obawę o możliwość zarażenia się chorobami psychicznymi, co wydaje się odzwierciedlać koncepcję pięt na udzi elo ne go $\mathrm{o}^{29}$, a więc stygmatyzacji oddzielonej od pierwotnego przedmiotu, ale wynikającej z bezpośredniego kontaktu z nim. Lęki studentów mogą wskazywać na typowy akt kalkulowania przez jednostkę dobrowolnie przyjmującą piętno, która staje przed dylematem przymusu akceptacji dyskomfortu wynikającego $\mathrm{z}$ reprezentowania grupy napiętnowanej. Adepci wskazują, że socjalizacja do piętna jest powiązana $\mathrm{z}$ aktywnością „n or mal só w”: lekarzy innych specjalności, dyskredytujących psychiatrię.

${ }^{24}$ C. Henderson, S. Evans-Lacko, G. Thornicroft, Mental Illness Stigma, Help Seeking, and Public Health Programs, "American Journal of Public Health" 2013, Vol. 103, No. 5, s. 777-780.

25 A. Kochański, A. Cechnicki, Opinie polskich psychiatrów o psychiatrii i własnej roli zawodowej, „Postępy Psychiatrii i Neurologii” 2018, t. 27, nr 1, s. 31-48.

26 M.C. Angermeyer, H. Matschinger, Public Attitude Towards Psychiatric Treatment, „Acta Psychiatrica Scandinavica” 1996, Vol. 94, No. 5, s. 326-336.

27 H. Qureshi, S. Carney, A. Iversen, Narrative Review of the Impact of Clinical Psychiatry Attachments on Attitudes to Psychiatry, „The Psychiatrist” 2013, Vol. 37, No. 3, s. 104-110.

28 WPA Guidance on how to Combat Stigmatization of Psychiatry and Psychiatrists, „Official Journal of The World Psychiatric Association” 2010, Vol. 9, No. 3, s. 131-144.

29 E. Goffman, op. cit., s. 19. 
W przypadku lekarzy psychiatrów inicjacyjny moment uczenia się piętna wydaje się przypadać właśnie na czas studiów medycznych. Poznając w tym czasie perspektywę „normalsów”, uczą się, że są z ich punktu widzenia dyskwalifikowani ${ }^{30}$. Jednocześnie już kilkudniowe praktyczne zajęcia z psychiatrii zmieniają tę narrację na bardziej przychylną ${ }^{31}$. Wiedza pozyskana wskutek własnej praktyki klinicznej jest więc jakościowo odmienna od tej pochodzącej od osób trzecich.

Paul Ricoeur za Charlesem Taylorem nazwał człowieka „zwierzęciem samointerpretującym się" 32 . Samointerpretacja psychiatrów odbywa się zwłaszcza przez autostygmatyzację. Jak wskazują Artur Kochański i Andrzej Cechnicki, polscy psychiatrzy „dzielą często dyskryminujące doświadczenia z osobami chorującymi psychicznie" 33 . Napiętnowani przez społeczeństwo i kolegów lekarzy internalizują i - w efekcie samospełniającej się przepowiedni - performują treści, których źródłem są powszechnie podzielane stereotypy i uprzedzenia. Wśród antycypowanych dyskryminujących treści psychiatrzy wymieniają przekonanie o nieskuteczności i nienaukowości psychiatrii oraz o możliwości zarażenia się szaleństwem. Piętno może być jednak źródłem drugorzędnych korzyści. Analiza wątku autostygmatyzacji ujawnia interesujący paradoks. Psychiatrzy, choć uważają swoją dziedzinę za „niedocenianą i dyskryminowaną", doświadczają wypalenia zawodowego, braku uznania, poczucia nieskuteczności, generalnego pesymizmu, to jednocześnie wyrażają „duże zadowolenie z wyboru tej specjalności lekarskiej”34. We własnych oczach są bardziej kulturalni, dojrzali, refleksyjni i mniej autorytarni w stosunku do pacjenta niż przedstawiciele innych specjalności.

\section{ZWIĄZKI}

Konfrontując wnioski z analizy obrazów filmowych z wynikami badań postaw społecznych, możemy zauważyć pewne zbieżne motywacje i taktyki dewaluacji. Proponuję wyodrębnienie trzech osi, tożsamych z obszarami

30 Ibidem.

31 H. Qureshi, S. Carney, A. Iversen, op. cit., s. 104-110.

32 P. Ricoeur, O sobie samym jako innym, tłum. B. Chełstowski, oprac. nauk. i wstęp M. Kowalska, Warszawa 2003, s. 297.

33 A. Kochański, A. Cechnicki, op. cit., s. 31-48.

34 Ibidem. 
najintensywniejszego lęku. Każda z narracji realizuje przynajmniej jeden wątek na jednej z proponowanych osi, choć często występują one równolegle lub przecinają się.

Naruszanie granic. Utrzymanie granic w relacji terapeutycznej jest podstawowym wskaźnikiem profesjonalizmu i poziomu etyczności specjalisty z zakresu zdrowia psychicznego. Zasady dotyczące granic w kontakcie pacjent - lekarz regulowane są przez kodeksy zawodowo-etyczne, a ich naruszenie może spotkać się z realnymi konsekwencjami prawnymi. Obowiązujące normy chronią interes pacjenta poprzez zapewnienie mu prawa do prywatności, intymności, bezpieczeństwa, dobrowolności, nietykalności cielesnej, jawnego dostępu do informacji. Zrozumienie roli tych wartości dla efektu leczenia i nauka sposobów ich realizacji stanowi bardzo ważny element w procesie edukacji specjalistów z zakresu zdrowia psychicznego. W narracjach filmowych wartości te są regularnie, intencjonalnie (lub nie) łamane. Zazwyczaj jest to wyrazem egoizmu i makiawelizmu bohatera. Bywa jednak, że naruszenie granic poprzez drobne akty wypadnięcia z roli świadczą pozytywnie o wartości moralnej postaci, jak w typie Dr Wonderful. Znów odsyła to do problemu podwójnej tożsamości, wyrażającego pragnienie o dominacji perspektywy czysto ludzkiej nad ekspercką w sytuacjach kryzysowych, jak gdyby narzędzia tej drugiej nie były wytworzone wyłącznie w celu pomocy. Relacja terapeutyczna z definicji jest asymetryczna, stąd granice stosunków lekarz - pacjent są w pewnym sensie wskaźnikiem hierarchii i utrzymywania porządku społecznego, w którym konieczne jest odgrywanie konkretnych ról. Wyznacza to pozorną relację władzy i uległości. Wątek naruszania granic służy także do stawiania pytania o podwójną tożsamość lekarza i możliwość czasowego zawieszenia jednej z ról: osoby prywatnej lub eksperta. Pozwala postawić pytania, a także snuć fantazje o ich wykluczaniu się. Wreszcie granice są kluczowe w omówionej wyżej kwestii efemeryczności i n iew idzial ności przedmiotu badań psychiatrii i stanowią kategorię powiązaną z zagadnieniem zarządzania piętnem.

Niekompetencja. Nieskuteczność i bezradność są właściwościami przypisywanymi figurom reprezentantów psychiatrii niezależnie od ich płci. Lęk o niekompetencję psychiatry w bezpośredni sposób koresponduje ze, wspomnianym wcześniej, jej szczególnym statusem wśród innych dyscyplin medycznych. Wśród lekarzy innych specjalności można mówić nie o lęku, a o przekonaniu czy domniemaniu niekompetencji psychiatrów. 
Kompleksy technologiczne dziedziny i jej wojny paradygmatyczne personifikuje się w postaciach szalonych, niezdarnych, nieskutecznych naukowców. Brudne ubrania, nieskuteczne leki, emanacje seksualności - wszystko to może odsyłać do symboli piętna, demaskujących rozbieżność tożsamości $i$ „redukujących konsekwentnie ocenę jednostki” ${ }^{35}$. Dziedzinie zarzuca się mniejszą od oczekiwanej skuteczność, zachowawczy charakter leczenia, brak satysfakcjonujących narzędzi diagnostycznych. Interwencje filmowych psychiatrów są więc prawie zawsze nieskuteczne, a jeśli wywołują efekt, to negatywny $-\mathrm{z}$ ubytkiem zdrowia lub nawet śmiercią pacjenta włącznie. Kategoria niekompetencji ujawnia społeczne niepokoje o istotę kultury eksperckiej. Eksploruje wizję, w której profesjonalizacja w zakresie zdrowia psychicznego stanowi próbę monetyzacji i kolonizacji przestrzeni pierwotnie intymnej. Pokazuje profesjonalizm jako wartość deficytową, a w pewnej jego wersji jako czynnik pogłębiający dystans w relacji lekarz pacjent. Zagadnienie to mocno koreluje z trudnościami instytucjonalnymi związanymi z leczeniem psychiatrycznym, a zwłaszcza jego ograniczeniami systemowymi.

Wrogo ść. Większość Gabbardowskich typów zakłada, że interesy pacjenta i lekarza są rozbieżne, przy czym lekarz nie ujawnia wprost swoich prawdziwych motywacji. Pragnie osiągnięcia kontroli nad społeczeństwem, zdobycia władzy i zasobów finansowych. Uprzedmiotawia pacjenta i manipuluje nim, by osiągnąć swój cel, często ujawniając wręcz sadyzm. Reprezentuje machinę biurokratyczną, tajne grupy wpływu, totalitaryzujący system lub bezduszne, niekorespondujące $\mathrm{z}$ codziennością instytucje naukowe. Zachowania pozornie wzbudzające zaufanie powinny wywołać czujność pacjenta, gdyż prawdopodobnie są elementem manipulacji. Ten paranoiczny wątek wydaje się mieć źródła w kilku zjawiskach. Po pierwsze - w motywacji lekarza. Wątpliwość budzi podejmowanie dobrowolnego kontaktu z osobami zaburzonymi, w myśl mechanizmu piętna udzielonego. Trudność w rozpoznaniu potencjalnej przyjemności osiąganej w realizacji tej pracy może skłaniać do podejrzeń, że prawdziwe korzyści leżą gdzie indziej, na przykład w wysokich zarobkach lub czerpaniu sadystycznej przyjemności. Po drugie - skonceptualizowanie psychiatry jako wrogiego

35 E. Goffman, op. cit. s. 19-21. 
mobilizuje pacjenta do jakiejkolwiek aktywności; jest to bardziej upodmiotawiające niż akceptacja relacji opartej na władzy i całkowitej uległości. Po trzecie - brak natychmiastowych efektów leczenia, satysfakcjonującej ulgi czy wreszcie sztywność lekarza w diagnozowaniu i interwencjach mogą być odbierane jako brak dostatecznego, empatycznego zaangażowania w leczenie. Po czwarte i najważniejsze - wrogość psychiatry może być wyrazem jego dominacji oraz pogardy wobec pacjenta i jego autonomiczności. Ten rodzaj władzy osiąga on poprzez posiadanie wiedzy: zarówno zasobów, których kumulacja pozwoliła mu na występowanie na danym stanowisku, jak i zdolności do nielegalnego zdobywania wiedzy o pacjencie przez niedobrowolną infiltrację oraz analizę jego życia psychicznego.

\section{WNIOSKI}

Sposób prezentacji psychiatrów w tekstach kultury jest konsekwentny, zniekształcony i intensywnie nasycony emocjonalnie. Można wyodrębnić kilka podstawowych kodów służących do przedstawiania psychiatrów, przy czym większość z nich służy tworzeniu figury zdewaluowanej. Przekazywane w ten sposób wartości wydają się wskazywać na kilka fundamentalnych lęków związanych z lekarzami psychiatrii. Dotyczą one kompetencji, władzy i naruszania granic. Cyrkulacja tych problemów zapewniana przez media masowe jest jednocześnie ściśle zależna od kontekstu historyczno-kulturowego i względnie stabilna. Niesione w nich znaczenia oddziałują z każdym $\mathrm{z}$ aktorów interakcji terapeutycznej, czego dowodem jest występowanie wspólnych treści lęków i stereotypów, przenikających między fikcją a rzeczywistością. Pacjenci nabywają stereotypowe przekonania o wyglądzie, sposobie zachowania, możliwościach i motywacjach lekarzy, skuteczności interwencji psychiatrycznych, oraz statusie dziedziny i podejmowanych przez nią zagadnieniach. Uczą się, że zaburzenia psychiczne to zjawisko marginalne, cechujące się skrajnościami, niewymagające medycznej konceptualizacji, czasem nawet kwestionując ich istnienie. Obawiają się psychiatry, podejrzewając go o wrogie intencje, niekompetencję czy „szaleństwo”, a przede wszystkim - przypisując mu omnipotencję. Tracąc zaufanie do specjalisty, podważają zasadność leczenia. Stereotypowe przekonania kształtują nierealistyczne nastawienia, także te pozytywne. Przedstawienia wyidealizowane prowokują irracjonalne roszczenia wobec mocy i zakresu działania lekarza. Tworzą wizję asymetrycznej relacji, w której pacjent jest wyłącznie 
przedmiotem oddziaływań i odbiorcą. Sugerują istnienie cudownych metod, wywołujących spektakularne, natychmiastowe pozytywne efekty.

Lekarze internalizują stereotypowe treści i dokonują autostygmatyzacji, a ich poglądy na własną pracę są intensywnie ambiwalentne ${ }^{36}$. Idealizując siebie, jednocześnie uważają się za stygmatyzowanych, utrwalają poczucie krzywdy, rozdźwięku, niezrozumienia, wyjątkowości i naznaczenia. Mechanizm ten przypomina konstrukt narcyzmu wrażliwego/ukrytego (vulnerable/covert narcissism). Powszechność i zakres uprzedzeń wobec reprezentantów psychiatrii pogłębiają tożsamościowy problem tej dyscypliny. Niski status psychiatrii wśród innych specjalizacji medycznych do niedawna próbowano kompensować jej medykalizacją. Próbując uzyskać status nauki niezwiązanej z dziedzinami humanistycznymi, nowożytna psychiatria wpadła w pułapkę redukcjonizmu. Dominacja szkoły psychiatrii biologicznej, będąca radykalną odpowiedzią środowiska naukowego na historyczną psychiatrię przednaukową, bagatelizując czynniki społeczno-kulturowe, doprowadziła nie tylko do wewnętrznych konfliktów, ale przede wszystkim do problemów ze skuteczną pomocą pacjentom. Brak zaplecza pozwalającego na zrozumienie zależności między sytuacją klasową jednostki, pochodzeniem etnicznym i innymi czynnikami kontekstualnymi utrudnia celną diagnozę i efektywne leczenie. Niedofinansowanie sektorapowodujące skrócenie czasu trwania spotkań z pacjentem, jest jednocześnie konsekwencją i przyczyną uprawiania pewnej wizji psychiatrii. Problemy wynikające z braku wiedzy humanistycznej, które po kryzysie tożsamościowym psychiatrii związanym z medykalizacją tylko się zintensyfikują, odzwierciedlają prognozy i zalecenia WPA. Instytucja wskazuje, że przewidywany rozwój technologii jeszcze mocniej wymusi konieczność proporcjonalnej koncentracji na czynniku specyficznie ludzkim. Zachęca reprezentantów psychiatrii do rozsądnej współpracy $z$ mediami, $z$ kolei twórcom tekstów kultury proponuje alternatywne rozwiązania, na przykład przyjęcie perspektywy mikrohistorycznej czy wręcz etnograficznej ${ }^{37}$. Umiejętności miękkie i zdolność do autorefleksji, dotychczas

36 W. Gaebel, H. Zaeske, J. Zielasek [et al.], Stigmatization of Psychiatrists and General Practitioners: Results of an International Survey, „European Archives of Psychiatry and Clinical Neuroscience" 2015, Vol. 265, No. 3, s. 189-197.

37 A. Czernikiewicz, Psychiatria w filmie. Czy rzeczywiście prawda czasu prawda ekranu?, „Psychiatra. Pismo dla Praktyków” 2018, nr 22, s. 7-25. 
stanowiące podstawowe narzędzie pracy pozamedycznych specjalistów z zakresu zdrowia psychicznego, okazują się centralne i dla lekarzy psychiatrów. Globalizacja, zintensyfikowane procesy urbanizacyjne i modernizacyjne, czy regularne ruchy migracyjne populacji już teraz kształtują nowy typ pacjenta.

Perspektywa antypsychiatryczna, rozpowszechniona również w antropologii, wydaje się widzieć nauki o zdrowiu psychicznym jako wypowiadające się zgodnym, jednoznacznym głosem, podczas gdy ich wewnętrzna narracja jest bezdyskusyjnie polifoniczna. W istocie uczestniczy w niej również głos redukcjonistycznego paradygmatu biomedycznego, do niedawna nieskłonny do dialogu. Mimo to „czujny gość jest w stanie usłyszeć wiele "głosów «”38. Można odnieść wrażenie, że antypsychiatryczny odbiorca bywa skłonny do rozwijania swojej motywacji aż do paradoksu. Rozpoczyna od solipsystycznych, a wręcz nihilistycznych konstatacji, zarzuca dziedzinie stawianie pytań pozornych (kiedy mowa o uniwersaliach, schematach, esencjach, odruchach, podobieństwach), a następnie płynnie przechodzi w bunt przed intersubiektywnością. Za pomocą wątków „katartycznego uleczenia” ${ }^{39}$ proponuje uznanie uniwersalnych, podstawowych i demokratycznych zjawisk (jak rodzicielska, czy romantyczna miłość) za wystarczające narzędzia leczenia.

Dyskurs jest narzędziem pozwalającym na utrzymanie określonych stosunków władzy. Popularną perspektywą jest więc przedstawianie psychiatry jako jej dzierżyciela, omnipotentnego, niebezpiecznego reprezentanta instytucji totalnej. Jednak

władza nie jest jedna, nie jest monolitem, nie jest jednokierunkowym procesem pomiędzy instytucją wydającą rozkazy a podwładnymi [...] jest obecna w najsubtelniejszych mechanizmach stosunków społecznych, [...] nawet w wyzwolicielskich tendencjach, które próbują ją kontestować ${ }^{40}$.

Zarządzanie strachem przed szaleństwem jest skutecznym mechanizmem kontroli społecznej. Wzbudzające niepokój i podejrzliwość figury nie są obojętne, bo „sposób mówienia, język, który zmienia się w sztywny

${ }_{38}$ P. Good, Language For Those Who Have Nothing - Mikhail Bakhtin and the Landscape of Psychiatry, New York 2001, s. 2.

${ }^{39}$ G.O. Gabbard, op. cit.

40 U. Eco, Semiologia życia codziennego, tłum. J. Ugniewska, P. Salwa, wstęp J. Ugniewska, Warszawa 1996, s. 308-306. 
porządek, ustanawia władzę"41 . Prezentowanie psychiatry jako narzędzia do tłumienia ludzkiej wolności tak długo, aż pacjent przestanie przypuszczać, że lekarzowi naprawdę może zależeć na jego zdrowiu, przez długi czas było opłacalne. Systemowe utrzymywanie jednostki jedynie w częściowym zdrowiu lub częściowym dostępie do leczenia to skuteczne ograniczenie wolności. Wzbudzanie generalnej niechęci do psychiatrii może kształtować jej ostatecznych odbiorców: klasę średnią i wyższą oraz osoby wykluczone społecznie. Klasowość swobodnego dostępu do opieki nad zdrowiem psychicznym konserwuje się jej minimalną obecnością w sektorze publicznej służby zdrowia. Utrzymywane w ten sposób stosunki władzy skutecznie zatrzymują kapitał, jakim jest zdrowie, w rękach jednej grupy. Radykalna reorganizacja tego systemu może nastąpić na przykład przy okazji przewidywanego gwałtownego wzrostu liczby przypadków niepełnosprawności spowodowanej zaburzeniami psychicznymi ${ }^{42}$, który, chcąc, nie chcąc, zdereguluje stosunki ekonomiczne.

We współczesnych dyskursach antropologii psychiatrii rezygnuje się z prostej opozycji scjentyzm - antyscjentyzm ${ }^{43}$. Wśród motywacji do analizy narracji nie znajdujemy już więc wyłącznie chęci dyskredytacji czy apologii dyscypliny. Narracje te, potraktowane jako rodzaj skryptów poznawczych, stają się narzędziem przydatnym w diagnozie krytycznych obszarów bieżącej rzeczywistości kulturowej. Różnorodność agensów tworzących kulturowe narracje, pluralizacja dyskursów okołomedycznych, kryzys kultury eksperckiej, a wreszcie nieuchronna rewolucja psychiatryczna być może staną się obiektem zainteresowania antropologii naglącej.

\section{Bibliografia}

Matthias C. Angermeyer, Herbert Matschinger, Public Attitude Towards Psychiatric Treatment, „Acta Psychiatrica Scandinavica” 1996, Vol. 94, No. 5.

Antropologia psychiatrii dzieci i młodzieży. Wybór tekstów, red. A. Witeska-Młynarczyk, Oficyna Naukowa, Warszawa 2018.

41 Ibidem.

42 Zob. https://www.who.int/news-room/fact-sheets/detail/depression [dostęp 11.08.2019].

43 Na przykład: Antropologia psychiatrii dzieci i młodzieży. Wybór tekstów, red. A. Witeska-Młynarczyk, Warszawa 2018. 
Albert Bandura, Teoria społecznego uczenia się, WN PWN, Warszawa 2007.

Roland Barthes, Mitologie, tłum. A. Dziadek, Wydawnictwo KR, Warszawa 2000. Laura Beachum, The Psychopathology of Cinema: How Mental Illness and Psychotherapy are Portrayed in Film, „Honors Projects” 2010, Vol. 56.

Dinesh Bhugra, Norman Sartorius, Andrea Fiorillo [et al.], EPA Guidance on how to Improve the Image of Psychiatry and of the Psychiatrist, „European Psychiatry" 2015, Vol. 30.

Jerome S. Bruner, Życie jako narracja, „Kwartalnik Pedagogiczny” 1990, nr 2.

Rita Charon, Narrative Medicine. Honoring the Stories of Illness, Oxford University Press, New York 2006.

Rita Charon, The Narrative Road to Empathy, [w:] H. Spiro, M.G. McCrea Curnen, E. Peschel, D. St James, Empathy and the Practice of Medicine: Beyond Pills and the Scalpel, Yale University Press, New Haven 1993.

Andrzej Czernikiewicz, Psychiatria w filmie. Czy rzeczywiście prawda czasu prawda ekranu?, „Psychiatra. Pismo dla Praktyków” 2018, nr 22.

Maria Thereza Bonilha Dubugras, Jair de Jesus Mari, José Francisco Fernandes Quirino dos Santos, The Image of Psychiatrist in Academy Award Winning Films from 1991 to 2001, „Revista de Psiquiatria do Rio Grande do Sul” 2007, Vol. 29, No. 1.

Umberto Eco, Semiologia życia codziennego, tłum. J. Ugniewska, P. Salwa, wstęp J. Ugniewska, Czytelnik, Warszawa 1996.

Dara Roth Edney, Mass Media and Mental Illness: A Literature Review, Canadian Mental Health Association, Ontario 2004, https://ontario.cmha.ca/wp-content/files/2012/07/mass_media.pdf.

Michel Foucault, Słowa i rzeczy. Archeologia nauk humanistycznych, tłum. T. Komendant, Słowo/obraz terytoria, Gdańsk 2005.

Wolfgang Gaebel, Harald Zaeske, Jürgen Zielasek [et al.], Stigmatization of Psychiatrists and General Practitioners: Results of an International Survey, „European Archives of Psychiatry and Clinical Neuroscience” 2015, Vol. 265, No. 3.

Glen O. Gabbard, Psychotherapy in Hollywood Cinema, „Australasian Psychiatry” 2001, Vol. 9, No. 4.

Glen O. Gabbard, Krin Gabbard, Psychiatry and the Cinema, American Psychiatric Association Publishing, Virginia 1999. 
Erving Goffman, Piętno. Rozważania o zranionej tożsamości, tłum. A. Dzierżyńska, J. Tokarska-Bakir, wstęp J. Tokarska-Bakir, Gdańskie Wydawnictwo Psychologiczne, Gdańsk 2005.

Peter Good, Language For Those Who Have Nothing - Mikhail Bakhtin and the Landscape of Psychiatry, Springer, New York 2001.

Claire Henderson, Sara Evans-Lacko, Graham Thornicroft, Mental Illness Stigma, Help Seeking, and Public Health Programs, „American Journal of Public Health" 2013, Vol. 103, No. 5.

Michał Herer, Michela Foucaulta wizja współczesności. Wiedza, władza i gry prawdy, http://www.ekologiasztuka.pl/pdf/f007herer.pdf [dostęp 19.04.2020].

Andrzej Kapusta, Performowanie szaleństwa: narracja i choroba psychiczna, [w:] Performatywne wymiary kultury, red. K. Skowronek, K. Leszczyńska, Libron - Filip Lohner, Kraków 2012.

Andrzej Kapusta, Filozofia ekstremalna. Wokół myśli krytycznej Michela Foucaulta, WUMCS, Lublin 2002.

Arthur Kleinman, The Illness Narratives: Suffering, Healing, and the Human Condition, Basic Books, New York 1988.

Artur Kochański, Andrzej Cechnicki, Opinie polskich psychiatrów o psychiatrii i własnej roli zawodowej, „Postępy Psychiatrii i Neurologii” 2018, t. 27, nr 1. Jacek Kochanowski, Wiedza jako władza i wiedza jako opór. Wokół koncepcji Marka Olssena, Johna Codda i Anne-Marie O’Neill, „Nauka i Szkolnictwo Wyższe" 2007, nr 1 (29).

Christopher Lasch, The Culture of Narcissism: American Life in An Age of Diminishing Expectations, Norton \& Co., New York 1991.

Mate Matas, Nady El-Guebaly, Allan Peterkin [et al.], Mental Illness and the Media: An Assessment of Attitudes and Communication, „The Canadian Journal of Psychiatry" 2017, Vol. 30, No. 1.

Medycyna narracyjna. Opowieści o doświadczeniu choroby w perspektywie medycznej i humanistycznej, red. M. Chojnacka-Kuraś, WUW, Warszawa 2019. Wojciech Otto, Wizerunki bohaterów z chorobami psychicznymi w polskim kinie, [w:] Medycyna w filmie, red. M. Ganczar, M. Oleszczyk, Homini, Kraków 2017. Paul Ricoeur, O sobie samym jako innym, tłum. B. Chełstowski, oprac. nauk. i wstęp M. Kowalska, WN PWN, Warszawa 2003.

Henna Qureshi, Stuart Carney, Amy Iversen, Narrative Review of the Impact of Clinical Psychiatry Attachments on Attitudes to Psychiatry, „The Psychiatrist” 2013, Vol. 37, No. 3. 
Norman Sartorius, Guidance on how to Combat Stigmatization of Psychiatry and Psychiatrists, „World Psychiatry” 2012, Vol. 11, No. 1.

Norman Sartorius, Wolfgang Gaebel, Helen-Rose Cleveland et al., WPA Guidance on how to Combat Stigmatization of Psychiatry and Psychiatrists, „World Psychiatry" 2010, Vol. 9.

Dominic Strinati, Wprowadzenie do kultury popularnej, tłum. W.J. Burszta, Zysk i S-ka, Poznań 1998.

Vieda Skultans, Anthropology and Narrative, w: Narrative Based Medicine. Dialogue and Discourse in Clinical Practice, eds. T. Greenhalgh, B. Hurwitz, BMJ Books, London 1998.

Garry Walter, The Stereotype of the Mad Psychiatrist, „Australian and New Zealand Journal of Psychiatry" 1989, Vol. 23.

Garry Walter, Andrew McDonald, Joseph Rey, Alan Rosen, Medical Student Knowledge and Attitudes Regarding ECT Prior to and After Viewing ECT Scenes from Movies, „The Journal of ECT” 2002, Vol. 18, No. 1.

WPA Guidance on how to Combat Stigmatization of Psychiatry and Psychiatrists, „Official Journal of The World Psychiatric Association” 2010, Vol. 9, No. 3.

\section{Between Texts of Culture and Clinical Practice. Narratives about Psychiatrists and Current Issues of the Field}

Narratives about psychiatry and psychiatrists, which appear in texts of culture, are clearly negative. Nevertheless, media images are the main source of common knowledge concerning the field. Several strategies of stereotyping psychiatrists in movie images can be distinguished. Social attitudes towards psychiatry, including these present among medical specialists, as well as psychiatrists themselves, reflect similar areas of devaluation. These problem fields are a valuable source of information about current problems within the discipline, and the condition of the cultural reality in which it is immersed.

Keywords: psychiatry, anthropology of psychiatry, doctor's image, stigmatization, self-stigmatization 